University of Nebraska - Lincoln

DigitalCommons@University of Nebraska - Lincoln

Faculty Publications, Department of Psychology

Psychology, Department of

2020

Nexus of Despair: A Network Analysis of Suicidal Ideation among

Veterans

Jeffrey S. Simons

Raluca M. Simons

Kyle J. Walters

Jessica A. Keith

Carol O'Brien

See next page for additional authors

Follow this and additional works at: https://digitalcommons.unl.edu/psychfacpub

Part of the Psychology Commons

This Article is brought to you for free and open access by the Psychology, Department of at

DigitalCommons@University of Nebraska - Lincoln. It has been accepted for inclusion in Faculty Publications, Department of Psychology by an authorized administrator of DigitalCommons@University of Nebraska - Lincoln. 


\section{Authors}

Jeffrey S. Simons, Raluca M. Simons, Kyle J. Walters, Jessica A. Keith, Carol O'Brien, Kate Andal, and Scott F. Stoltenberg 
Published in Archives of Suicide Research 24:sup1 (2020), pp. S314-S336; doi: 10.1080/13811118.2019 .1574689

Copyright (C) 2019 International Academy for Suicide Research. Published by Routledge/Taylor \& Francis Group. Used by permission.

Submitted August 2, 2018; accepted January 22, 2019; published online March 24, 2019.

\title{
Nexus of Despair: A Network Analysis of Suicidal Ideation among Veterans
}

\author{
Jeffrey S. Simons, ${ }^{1}$ Raluca M. Simons, ${ }^{2}$ Kyle J. Walters, ${ }^{1}$ Jessica A. Keith, ${ }^{3}$ \\ Carol O'Brien, ${ }^{3 *}$ Kate Andal, $^{4}$ and Scott F. Stoltenberg ${ }^{5}$
}

1. Department of Psychology, University of South Dakota, Vermillion, South Dakota, USA

2. Department of Psychology, Disaster Mental Health Institute, University of South Dakota, Vermillion, South Dakota, USA

3. Bay Pines VA Health Care System, Bay Pines, Florida, USA

4. Sioux Falls VA Health Care System, Sioux Falls, South Dakota, USA

5. Department of Psychology, University of Nebraska-Lincoln, Lincoln, Nebraska, USA

${ }^{*}$ Carol O'Brien is now in private practice.

Corresponding author - Jeffrey S. Simons, Department of Psychology, University of South Dakota, Vermillion, SD, 57069, email jsimons@usd.edu

\begin{abstract}
The objective of this study was to estimate a network model of risk and resilience factors of suicidal ideation among veterans. Two network models of suicidal ideation among Operation Iraqi Freedom/ Operation Enduring Freedom/Operation New Dawn veterans $(N=276)$ incorporated key disorders, traumatic stress, and resilience constructs to contextualize suicidal ideation. Childhood trauma was positively connected with suicidal ideation and harassment and inversely connected with social support and distress tolerance. This exemplifies long-lasting associations between childhood trauma and revictimization, emotion regulation, and ability to form supportive social relationships. A subsequent model including lower-order facets indicated that combat trauma was predominantly associated with posttraumatic stress disorder-intrusion symptoms. This study highlights the importance of addressing both risk and resilience to reduce suicide risk among veterans and increases understanding of factors that contribute to suicidal ideation.
\end{abstract}

Keywords: alcohol, emotion regulation, network analysis, self-control, suicide, traumatic stress 
Suicide is the 10th leading cause of death in the United States, and rates of death by suicide have increased in recent years contributing to approximately $1.6 \%$ of deaths in 2015 (National Center for Health Statistics, 2017). Veterans have been identified as a high-risk group for suicide (Kaplan, Huguet, McFarland, \& Newsom, 2007). Some studies have raised questions about this basic issue, suggesting a more complex association between military service experience and suicide risk (Gibbons, Brown, \& Hur, 2012; Miller et al., 2012). Nonetheless, the most comprehensive report to date indicates that, adjusting for differences in age and sex, risk for suicide among veterans is $22 \%$ higher than the general population (U.S. Department of Veteran Affairs, 2017). Risk for suicide among veterans is a pressing public health concern and identifying those at risk and developing effective prevention programs is a top priority of the Veteran's Health Administration (U.S. Department of Veteran Affairs, 2017). However, as alarming as the rates of suicide are, it is an extremely low base-rate behavior, and the identification of robust risk factors for suicide, or even more prevalent proximal risk factors such as suicidal ideation, is extremely difficult. In the current study, we take an innovative approach by estimating a network model of suicidal ideation among veterans to advance understanding of the complex array of factors associated with suicidal ideation.

\section{Network Models}

Network models have become an increasingly popular approach to studying psychopathology in recent years (Borsboom, 2017; Borsboom, Cramer, Schmittmann, Epskamp, \& Waldorp, 2011; Cramer, Waldorp, van der Maas, \& Borsboom, 2010). For example, recent research has used network models to identify core symptoms of posttraumatic stress disorder (PTSD) and bridge symptoms contributing to comorbidity between PTSD and depression (Armour, Fried, Deserno, Tsai, \& Pietrzak, 2017; Bryant et al., 2017; Mitchell et al., 2017). In contrast to traditional latent variable models of psychopathology, network models conceptualize interrelated symptoms as disorder rather than a manifestation of an underlying disease process (Cramer, Waldorp, van der Maas, \& Borsboom, 2010). Such a conceptualization may be more consistent with the observed heterogeneity in diagnostic categories in the DSM-5 (American Psychiatric Association, 2013; Olbert, Gala, \& Tupler, 2014) and provide a better template for modeling comorbidity between disorders (Cramer et al., 2010). Network models of psychopathology map the strength and pattern of associations between symptoms based on partial correlations (Epskamp, Borsboom, \& Fried, 2018). Measures of centrality quantify how strongly associated a symptom is in respect to the entire network (Epskamp et al., 2018). In theory, identifying symptoms that are most central to the network, or bridge between disorders, may be an avenue for advancing understanding of the etiology, course, and/or comorbidity of disorders (Cramer et al., 2010).

More broadly, network models in psychology generally estimate the association of each pair of nodes conditional upon all other nodes in the network, i.e., a partial correlation matrix (Epskamp et al., 2018). Nodes need not be symptoms per se but are any variable whose relationship to other variables can be quantified and conceptualized as a network of interrelated factors (Armour et al., 2017; Jones, Heeren, \& McNally, 2017). For example, network models have been used to examine linkages between alcohol use disorder, 
drinking motives, and other forms of psychopathology (Anker et al., 2017) as well as PTSD symptoms and clinical covariates (Armour et al., 2017). Network models are consistent with the logic of graph theory in structural causal models in that they estimate conditional independencies (Kline, 2016; Pearl, 1998). However, in contrast to directed graphs and, more broadly, structural equation models (Kline, 2016), undirected network models exhibit bidirectional associations, and hence there are no alternative models that exhibit the same fit to the data (e.g., reverse causal direction; Epskamp et al., 2018). Indeed, the "oneway causal flow" characteristic of common recursive structural equation models is more often imposed on statistical models than theoretically justified. Many psychological constructs likely have dynamic reciprocal associations over time. In respect to factors associated with suicide, excessive alcohol consumption may be both a cause and consequence of depression and suicidal ideation (Pompili et al., 2010; Schuckit, Smith, \& Kalmijn, 2013). Depression and suicidal ideation may be expected to have reciprocal associations with social support (Kleiman, Liu, \& Riskind, 2014; Liu, 2013; Liu \& Alloy, 2010; Miller, EspositoSmythers, \& Leichtweis, 2015). Similarly, executive functioning and emotional arousal are known to reciprocally influence each other (Aupperle, Melrose, Stein, \& Paulus, 2012; Pessoa, 2009).

Finally, human behavior and psychological phenomena are inherently complex. Sample sizes in psychology often limit the complexity of models one can estimate using common techniques such as SEM. A substantial appeal of the network model approach is the ability to estimate quite complex structures with comparatively few observations. This is made possible by application of the least absolute shrinkage and selection operator (LASSO; Tibshirani, 1996), which minimizes the number of partial correlations needed to fit the observed covariance matrix. Since the LASSO constrains small observed covariances to zero, sensitivity may be diminished. However, the models exhibit high specificity (Epskamp \& Fried, 2016). Despite the potential complexity of network models with many nodes, graphical representations of the network provide a compelling way to present fairly complex data as a coherent picture in which patterns can be more easily surmised.

The above characteristics of network models make them an appealing approach to studying suicide. Suicide and suicidal ideation are likely the result of many small and potentially distal effects, which themselves may exhibit complex reciprocal associations. Indeed, such factors have given rise to interest and efforts to employ machine learning algorithms to this area (Franklin et al., 2017; Kessler et al., 2015). Despite the advantages of such approaches, network analyses provide a valuable alternative that can estimate complex associations to describe relationships among many theoretically relevant nodes (de Beurs, 2017; de Beurs, van Borkulo, \& O'Connor, 2017). In contrast to the work of de Beurs and colleagues, we will test a network of factors associated with suicidal ideation rather than the constellation of suicidal ideation symptoms themselves.

\section{Suicide Risk and Resilience Factors}

Previous research has identified many risk factors for suicide in the general population, yet a recent meta-analysis indicates that none are a clinically significant predictor of either completed suicide or suicidal ideation over time (Franklin et al., 2017). Suicide and suicidal 
ideation may be related to a high number of risk and protective factors, each of which has only modest predictive value. Although effects are quite modest, Franklin et al. (2017) identified prior psychiatric hospitalization, suicide attempts, suicidal ideation, low SES, and stressful life events as the top five predictors of completed suicide. In respect to suicidal ideation, hopelessness, depression diagnosis, abuse history, anxiety, and prior suicidal ideation were the top five predictors. Low social support, the immediate postdischarge period, and continuity of care have also been identified as predictors of suicide (Troister, Links, \& Cutcliffe, 2008). Recent meta-analyses indicate alcohol and other substance use disorder are significantly associated with suicidal ideation and suicide (Darvishi, Farhadi, Haghtalab, \& Poorolajal, 2015; Poorolajal, Haghtalab, Farhadi, \& Darvishi, 2016). Among veterans, demographic factors such as male gender, younger age, being unmarried, and being White exhibit positive bivariate associations with suicide (Schoenbaum et al., 2014). In addition, among those with a recent psychiatric hospitalization, previous criminal assault or weapons offenses; days hospitalized for depression, somatoform, or dissociative disorder; and suicidal ideation are among a host of factors prospectively associated with suicide (Kessler et al., 2015). Interestingly, the predictive algorithm indicated that high rates of psychiatric hospitalization and the presence of a PTSD diagnosis were inversely associated with suicide. Such anomalous findings are perhaps an indication of the inherent differences between constructing risk algorithms vs. identifying potential risk factors per se. However, findings of the association between suicide risk and PTSD have been mixed in veteran populations with positive, inverse, and null effects (Krysinska \& Lester, 2010; Pfeiffer, Ganoczy, Ilgen, Zivin, \& Valenstein, 2009; Zivin et al., 2007).

\section{Current Study}

We test a network model of factors relevant to suicide risk among veterans. Our selection of constructs was guided by two overarching premises. First, both risk and resilience factors are important to consider in a model of suicidal ideation (Mash, Naifeh, Fullerton, Morganstein, \& Ursano, 2018; Rudd, 2014). Second, clinical practice guidelines (Rudd, 2014) highlight the importance of multiple assessment domains, including predisposing factors (e.g., trauma or abuse history), symptomatic severity (e.g., depression, anxiety, substance abuse), emotional and behavioral regulation (e.g., self-control), and protective factors (e.g., social support) in addition to suicide-specific factors (e.g., plans, means, lethality). Thus, in addition to suicidal ideation, we included variables from four broad classes (psychiatric disorder severity, social support, traumatic stress, and cognitive/emotional resilience traits). Symptom severity of three disorders, depression, alcohol use disorder, and PTSD were included as these are prevalent disorders in the population and each has been associated with risk for suicide in previous research (American Psychiatric Association, 2013; Bryan, Garland, \& Rudd, 2016; Franklin et al., 2017; Guerra \& Calhoun, 2011; Herberman Mash et al., 2016; Kessler et al., 2015; Smith, Goldstein, \& Grant, 2016). In respect to social support, we include support from friends and family, given the importance of social support in models of mental health and the observed increased risk for those unmarried with no dependents (Kleiman, Riskind, \& Schaefer, 2014; Schoenbaum et al., 2014). In addition, we include support from the unit in respect to both training/preparation and 
perceived support, as these may be particularly relevant for veterans (Griffith, 2015; Pietrzak et al., 2010; Vogt, Smith, King, \& King, 2012). We include combat trauma, childhood trauma, and military sexual trauma and bullying to examine the associations of traumatic stress in the network (Hahn, Tirabassi, Simons, \& Simons, 2015; Simons et al., 2017). Finally, we include two resilience factors that are theoretically related to suicidal ideation, effortful control and distress tolerance. Poor self-control and low distress tolerance are factors associated with traumatic stress and PTSD (Marshall-Berenz, Vujanovic, Bonn-Miller, Bernstein, \& Zvolensky, 2010; Simons et al., 2017; Vujanovic, Marshall-Berenz, \& Zvolensky, 2011) and associated with increased suicidal ideation (Anestis, Bagge, Tull, \& Joiner, 2011; Klonsky \& May, 2010). We estimate two models. The first includes the global constructs described above to evaluate associations between the constructs. In the second, we include lower-order factors of distress tolerance, PTSD symptoms, and depression to examine associations with more specific classes of symptoms. Higher-order constructs, such as PTSD, are heterogenous (Olbert et al., 2014). Such heterogeneity may obscure the nature of relationships between constructs, which may be clarified in the analysis with the lowerorder factors. Conversely, the inclusion of several highly correlated lower-order factors has the potential to distort the implied associations between the parent constructs. Hence, the two models have complementary advantages. We acknowledge the inherent difficulty in establishing a priori the most relevant constellation of constructs to include in the network. However, we believe that the previously established associations among these constructs, their relative fit with clinical practice guidelines, and their relevance to veteran populations makes them a reasonable starting point for an as of yet unknown optimal universe of risk and resilience factors of suicidal ideation.

\section{Method}

\section{Participants}

Participants were 276 Operation Iraqi Freedom/Operation Enduring Freedom/Operation New Dawn (OIF/OEF/OND) veterans age 21-51 $(M=33.31, S D=6.57)$. Fourteen percent were women. The sample was $82 \%$ White, $10 \%$ Black, 3\% multiracial, $1 \%$ Asian, and $5 \%$ other races or did not respond. Eight percent were Hispanic. Additional detail regarding sample characteristics can be found in two previous papers based on this sample (Simons et al., 2017, 2018).

\section{Measures}

\section{PTSD symptoms}

The 17-item National Center for PTSD Checklist-Military Version was used to assess PTSD symptoms (Blanchard, Jones-Alexander, Buckley, \& Forneris, 1996; Weathers, Litz, Herman, Huska, \& Keane, 1993). The PCL-M items correspond to DSM-IV criteria and symptoms are rated on a 5-point scale. The scale is internally consistent ( $\alpha=.97$ in the current sample) and has good sensitivity (.82) and specificity (.83) in predicting PTSD diagnoses among veterans (Weathers et al, 1993). The total score was used in the initial analysis. For the analysis of the lower-order scales, we created four subscales corresponding to 
the DSM- 5 symptom domains of intrusion symptoms ( 5 items, $\alpha=.94$, e.g., "repeated disturbing memories"), avoidance symptoms ( 2 items, $\alpha=.87$, e.g., "avoid thinking or talking about experience"), negative alterations in cognition and mood ( 5 items, $\alpha=.91$, e.g., "feeling emotionally numb"), and hyperarousal (5 items, $\alpha=.94$, e.g., "feeling jumpy or easily startled").

\section{Depression and suicidal ideation}

The Center for Epidemiological Studies Depression Scale-Revised assessed symptoms of depression (Eaton, Smith, Ybarra, Muntaner, \& Tien, 2004). Consistent with recommendation, each item was scored on a 4-pont scale $(0=$ not at all to $3=5-7$ days per week; Eaton et al., 2004). Of the 20 items, two were used to assess suicidal ideation ("I wished I were dead" and "I wanted to hurt myself"). The remaining 18 assessed depression symptoms $(\alpha=.95)$.

\section{The Deployment Risk and Resilience Inventory -2}

The Deployment Risk and Resilience Inventory -2 (DRRI-2; Vogt et al., 2012) was used to assess traumatic stress and social support. We included three traumatic stress constructs: childhood trauma; intimidation and sexual harassment during deployment; and combatrelated trauma. We included two social support constructs, support from family and friends, and unit support and preparation.

Combat-related trauma. The combat experiences ( 17 items) and battle aftermath (13 items) subscales are rated on 6-point scales $(1=$ Never, $6=$ Daily or almost daily $)$. Sample items include, "I was exposed to hostile incoming fire," and "I saw civilians after they had been severely wounded or disfigured." The mean of the 30 items of the two scales were combined into a single variable representing combat-related traumatic stress $(\alpha=.97)$.

Intimidation and sexual harassment. The harassment subscale consists of 8 items reflecting general harassment, intimidation, and bullying (e.g., condescension, threats to physical safety) and 8 items assessing sexual harassment (e.g., offensive sexual remarks, rape) during deployment. Each item is rated on a 4 -point scale $(1=$ never, $4=$ many times $)$. The mean of the 16 items was used $(\alpha=.88)$.

Childhood trauma. Childhood trauma was assessed by 5 dichotomous items from the predeployment stressors subscale $(\alpha=.72)$. The items assessed interpersonal traumatic stress that occurred before age 18. Items include: (1) "I saw or heard physical fighting between my parents or caregivers," (2) "I was physically punished by a parent or primary caregiver," (3) "I experienced unwanted sexual activity as a result of force, threat of harm, or manipulation during childhood (before age 18)," (4) "I was emotionally mistreated (for example, ignored or repeatedly told I was no good)," and (5) "I was seriously physically injured by another person (for example, hit or beaten up) during childhood (before age 18)."

Social support. Support from friends and family during and after deployment was assessed by three subscales assessing family/friend support during (8 items) and after 
deployment (10 items) and post-deployment family relationships (12 items). Items are rated on a 5 -point scale $(1=$ strongly disagree, $5=$ strongly agree $)$. The mean of all items was used $(\alpha=.96)$.

Unit support. Unit support included 10 items assessing training and preparation and 12 items reflecting perceived social support from unit members during deployment. Items are rated on a 5 -point scale $(1=$ strongly disagree, $5=$ strongly agree $)$. The mean of all items was used $(\alpha=.94)$.

Alcohol dependence symptoms. The Alcohol Dependence Scale (ADS; Skinner \& Allen, 1982; Skinner \& Horn, 1984) was used to assess symptoms of alcohol dependence syndrome. The scale contains 25 items $(\alpha=.88)$ that assess loss of control over drinking and exhibits good convergent validity with other indicators of alcohol use disorder (AUD; Doyle \& Donovan, 2009). Scale anchors vary across item. The total score was used in the analysis.

Effortful control. Effortful control was defined by three indicators: (1) A 7-item measure of planfulness (Kendall \& Williams, 1982), (2) 6-item measure of problem solving (Wills et al., 2001), and (3) a 10-item goal-setting scale (SSRQ; Neal \& Carey, 2005). High scores indicate greater self-control $(\alpha=.77)$. Previous factor analysis with these items form a cohesive factor of self-control (Simons, Wills, Emery, \& Spelman, 2016).

Distress tolerance. The Distress Tolerance Scale consists of 15 items that are indicators of four factors (appraisal, regulation, tolerance, and absorption) that load onto a higher order general factor. The appraisal factor assesses acceptance of negative emotional experience, self-efficacy for regulating emotions, and maintaining a positive self-image despite negative feeling states (6 items). Regulation assesses efforts to terminate distress ( 3 items). Absorption assesses the ability to maintain goal-directed behavior when distressed ( 3 items). Tolerance assesses perceptions of distress as being bearable ( 3 items). The higher order scale and lower order scales were internally consistent $(\alpha=.77-.84)$. Previous research supports the factor structure and construct validity of the scale (Leyro, Bernstein, Vujanovic, McLeish, \& Zvolensky, 2011; Sandin, Simons, Valiente, Simons, \& Chorot, 2017; Simons \& Gaher, 2005).

\section{Procedure}

OIF/OEF/OND veterans were recruited from two communities (Tampa Bay area, Florida, and Vermillion/Sioux Falls, South Dakota). Participants were recruited from the local Veteran Affairs Medical Centers, local universities, and surrounding communities via newspaper advertisements, flyers, mail correspondence, and clinician referral. Participants completed a baseline assessment as part of a larger experience sampling study, data from which is not included in this manuscript. Participants were paid $\$ 25$ for the baseline assessment. Participation was voluntary and responses were confidential. 


\section{Data analysis}

We used network analysis to explore relationships between suicidal ideation and potential vulnerability and resilience factors. We estimate two networks. The first network explores relationships at a global level. That is, relationships between suicidal ideation, symptom severity (i.e., PTSD, AUD, and major depression [not including the suicidal ideation symptoms]), traumatic stress (i.e., combat trauma, childhood trauma, and harassment), resilience factors (i.e., distress tolerance and effortful control), and social support. The second network incorporates lower-order factors of three constructs to assess associations between more specific classes of symptoms. We did not examine lower-order factors or symptom level indicators for all constructs due to the relatively small sample. The three chosen have established subdomains in the literature and were among the most central in the global network. The PTSD construct was replaced by DSM-5 symptom domains of Arousal, Avoidance, Intrusions, and Negative alterations in cognition and mood (American Psychiatric Association, 2013). Major depression was represented by two factors, Somatic and Mood-Cognitive symptoms (Elhai et al., 2012). Distress Tolerance was represented by the four subscales of the DTS, Appraisal, Absorption, Tolerance, and Regulation (Simons \& Gaher, 2005).

Pairwise Markov Random Field network models estimate the direct associations that symptoms or constructs have with each other by estimating partial correlations (Costantini et al., 2015). That is, these undirected network models display the association between any two nodes with the associations of the rest of the nodes in the network partialed out. Each symptom or construct is represented as a node in the network and the partial correlation between two nodes is represented by an edge. Edges are undirected (i.e., they do not imply directionality) and weighted with the magnitude of their corresponding partial correlation. Nodes can be inspected for their relevance within the network using indices of centrality (e.g., betweenness, closeness, and strength; Borsboom \& Cramer, 2013). However, these indices may not have a clear interpretation in networks with a mixture of positive and negative edges (Robinaugh, Millner, \& McNally, 2016).1

\section{Network estimation}

We estimated both networks using the R package bootnet (Epskamp et al., 2018), which calls the ggraph package (Epskamp, Cramer, Waldorp, Schmittmann, \& Borsboom, 2012). This approach uses the Gaussian Graphical Model to yield pairwise partial correlations between all nodes (Epskamp et al., 2018). Suicidal ideation and childhood trauma were specified as ordinal variables and the remainders were specified as continuous. Thus, polychoric correlations were used as input. The first network has 12 nodes, and therefore 66 pairwise associations would be estimated. The second network has 18 nodes, and thus 153 pairwise association parameters would be estimated. However, qgraph uses a graphical LASSO procedure (Tibshirani, 1996) that regularizes the network by identifying only the most relevant edges, thus reducing the number of false positive associations. The LASSO optimizes fit by using the Extended Bayesian information criterion (EBIC) as well as an adjustable hyperparameter $(\gamma)$. We chose the default value $(\gamma=0.5)$ which balances between sparsity and discovery. We used nonparametric bootstrapping to determine significant differences in model edges (Epskamp et al., 2018). 


\section{Results}

\section{Descriptive statistics}

Tables 1 and 2 present descriptive statistics and bivariate correlations. A substantial percent of the sample exceeded recommended cut-scores on the PCL indicating a potential PTSD diagnosis. Sixty-six percent exceeded a cut score of 36, and $43 \%$ exceeded the more conservative cut score of 50 recommended for Veteran affairs (VA) specialty clinics (U.S. Department of Veteran Affairs, 2012). Approximately 37\% scored 9 or higher on the ADS, suggesting a potential AUD diagnosis (Skinner \& Horn, 1984). Suicidal ideation exhibited moderate positive correlations with symptoms of PTSD, AUD, depression, and sexual harassment and bullying. Correlations between suicidal ideation and childhood trauma and combat trauma were slightly weaker. Distress tolerance and social support exhibited moderate inverse associations with suicidal ideation. Age was not significantly correlated with any variable aside from AUD symptoms. Correlations between the study constructs and gender were quite modest, with the largest $(r=-.33)$ indicating that women had more experience of sexual harassment and bullying from unit members relative to men.

\begin{tabular}{|c|c|c|c|c|c|c|c|}
\hline Variable & $N$ & $M$ & $S D$ & Min & Max & Skewness & Kurtosis \\
\hline Age & 275 & 33.31 & 6.57 & 21.00 & 51.00 & 0.53 & 2.59 \\
\hline PCL-total & 274 & 47.53 & 19.01 & 17.00 & 85.00 & 0.13 & 1.90 \\
\hline PCL-avoidance & 275 & 2.67 & 1.34 & 1.00 & 5.00 & 0.29 & 1.81 \\
\hline $\begin{array}{l}\text { PCL-neg. affect } \\
\text { cognition }\end{array}$ & 275 & 2.66 & 1.23 & 1.00 & 5.00 & 0.28 & 1.86 \\
\hline PCL-arousal & 275 & 3.19 & 1.20 & 1.00 & 5.00 & -0.21 & 1.88 \\
\hline PCL-intrusion & 275 & 2.61 & 1.17 & 1.00 & 5.00 & 0.39 & 2.01 \\
\hline ADS & 264 & 7.64 & 6.80 & 0.00 & 38.00 & 1.19 & 4.43 \\
\hline CESD-R & 274 & 17.37 & 13.97 & 0.00 & 54.00 & 0.84 & 2.75 \\
\hline CESDR-mood & 274 & 0.84 & 0.88 & 0.00 & 3.00 & 1.03 & 2.96 \\
\hline CESDR-somatic & 274 & 1.01 & 0.75 & 0.00 & 3.00 & 0.68 & 2.55 \\
\hline Suicidal ideation & 272 & 0.30 & 0.71 & 0.00 & 3.00 & 2.57 & 8.99 \\
\hline Childhood trauma & 273 & 0.98 & 1.35 & 0.00 & 5.00 & 1.37 & 3.99 \\
\hline Combat trauma & 276 & 2.19 & 1.05 & 1.00 & 6.00 & 1.18 & 3.90 \\
\hline Harassment & 276 & 0.53 & 0.46 & 0.00 & 2.56 & 1.06 & 4.00 \\
\hline Unit support & 276 & 3.65 & 0.85 & 1.27 & 5.00 & -0.55 & 2.44 \\
\hline Social support & 276 & 3.69 & 0.90 & 1.00 & 5.00 & -0.67 & 2.89 \\
\hline Self-control & 274 & 3.75 & 0.58 & 2.11 & 5.00 & -0.58 & 3.05 \\
\hline DTS & 272 & 3.33 & 0.95 & 1.08 & 5.00 & -0.21 & 2.35 \\
\hline DTS-tolerance & 271 & 3.35 & 1.14 & 1.00 & 5.00 & -0.30 & 2.15 \\
\hline DTS-absorption & 271 & 3.47 & 1.10 & 1.00 & 5.00 & -0.35 & 2.24 \\
\hline DTS-appraisal & 272 & 3.44 & 0.99 & 1.00 & 5.00 & -0.22 & 2.24 \\
\hline DTS-regulation & 272 & 3.07 & 1.13 & 1.00 & 5.00 & 0.15 & 2.11 \\
\hline
\end{tabular}

Note: PCL: PTSD checklist; neg. affect cognition: negative alterations in cognition and mood; ADS: Alcohol Dependence Scale; CESD-R: Center for Epidemiological Studies Depression Scale-Revised; DTS: Distress Tolerance Scale 


\begin{tabular}{|c|c|c|c|c|c|c|c|c|c|c|c|c|c|c|c|c|c|c|c|c|c|c|}
\hline Variable & 1 & 2 & 3 & 4 & 5 & 6 & 7 & 8 & 9 & 10 & 11 & 12 & 13 & 14 & 15 & 16 & 17 & 18 & 19 & 20 & 21 & 22 \\
\hline 1. Age & 1.00 & & & & & & & & & & & & & & & & & & & & & \\
\hline 2. Gender & .03 & 1.00 & & & & & & & & & & & & & & & & & & & & \\
\hline 3. PCL-total & .04 & -.04 & 1.00 & & & & & & & & & & & & & & & & & & & \\
\hline 4. PCL-avoi & .01 & -.10 & .89 & 1.00 & & & & & & & & & & & & & & & & & & \\
\hline 5. PCL-neg & .04 & -.04 & .93 & .78 & 1.00 & & & & & & & & & & & & & & & & & \\
\hline 6. PCL-arou & .01 & .01 & .93 & .76 & .83 & 1.00 & & & & & & & & & & & & & & & & \\
\hline 7. PCL-intr & .05 & -.04 & .92 & .83 & .78 & .78 & 1.00 & & & & & & & & & & & & & & & \\
\hline 8. ADS & -.14 & .02 & .46 & .42 & .47 & .41 & .40 & 1.00 & & & & & & & & & & & & & & \\
\hline 9. CESD-R & .02 & -.12 & .72 & .62 & .72 & .66 & .62 & .48 & 1.00 & & & & & & & & & & & & & \\
\hline 10. CESD-M & .05 & -.13 & .67 & .59 & .70 & .58 & .58 & .45 & .94 & 1.00 & & & & & & & & & & & & \\
\hline 11. CESD-S & -.01 & -.10 & .71 & .60 & .69 & .66 & .60 & .47 & .97 & .84 & 1.00 & & & & & & & & & & & \\
\hline 12. Suicidal & .05 & -.02 & .40 & .33 & .43 & .33 & .36 & .36 & .56 & .59 & .50 & 1.00 & & & & & & & & & & \\
\hline 13. Child tr & .10 & -.13 & .25 & .24 & .22 & .25 & .22 & .14 & .25 & .23 & .24 & .22 & 1.00 & & & & & & & & & \\
\hline 14. Combat tr & -.02 & .13 & .54 & .47 & .47 & .47 & .57 & .19 & .35 & .33 & .34 & .24 & .10 & 1.00 & & & & & & & & \\
\hline 15. Harass & -.03 & -.33 & .27 & .25 & .26 & .25 & .26 & .21 & .39 & .38 & .36 & .30 & .33 & .00 & 1.00 & & & & & & & \\
\hline 16. Unit sup. & -.08 & .20 & -.21 & -.22 & -.21 & -.23 & -.15 & -.06 & -.20 & -.16 & -.21 & -.17 & -.22 & .10 & -.42 & 1.00 & & & & & & \\
\hline 17. Social s. & -.03 & .05 & -.50 & -.45 & -.52 & -.45 & -.42 & -.38 & -.53 & -.50 & -.51 & -.43 & -.32 & -.22 & -.23 & .39 & 1.00 & & & & & \\
\hline 18. ECSC & .03 & -.06 & .21 & -.18 & -.24 & -.20 & -.14 & -.32 & -.37 & -.32 & -.39 & -.30 & -.12 & -.08 & -.16 & -.18 & .37 & 1.00 & & & & \\
\hline 19. DTS & -.03 & .12 & -.60 & -.58 & -.57 & -.53 & -.55 & -.45 & -.62 & -.62 & -.58 & -.38 & -.29 & -.24 & -.29 & .18 & .37 & .23 & 1.00 & & & \\
\hline 20. DTS-tol. & -.06 & .13 & -.50 & -.49 & -.47 & -.45 & -.44 & -.35 & -.54 & -.54 & -.50 & -.30 & -.22 & -.21 & -.28 & .16 & .30 & .18 & .89 & 1.00 & & \\
\hline 21. DTS-abs. & -.04 & .14 & -.54 & -.49 & -.55 & -.49 & -.46 & -.44 & -.62 & -.63 & -.58 & -.36 & -.29 & -.20 & -.28 & .13 & .38 & .21 & .90 & .77 & 1.00 & \\
\hline 22. DTS-app. & -.07 & .13 & -.62 & -.61 & -.60 & -.54 & -.57 & -.46 & -.63 & -.62 & -.59 & -.43 & -.31 & -.25 & -.29 & .25 & .44 & .32 & .89 & .74 & .76 & 1.00 \\
\hline 23. DTS-reg. & -.06 & .02 & -.43 & -.44 & -.39 & -.37 & -.44 & -.34 & -.41 & -.41 & -.40 & -.27 & -.21 & -.18 & -.16 & .06 & .19 & .11 & .82 & .60 & .60 & .62 \\
\hline
\end{tabular}

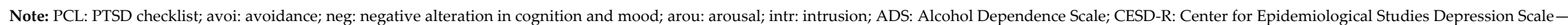

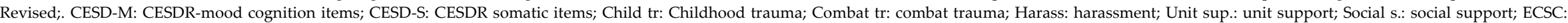
effortful control; DTS: Distress Tolerance Scale; DTS-tol.: DTS tolerance items; DTS-abs.: DTS absorption items; DTS-app.: DTS appraisal items; DTS-reg.: DTS regulation items.

$|r| \geq .12, p<.05$

$|r| \geq .16, p<.01$

$|r| \geq .20, p<.001$ 


\section{Global network}

A fully connected network with 11 nodes would contain 55 edges. After applying the LASSO procedure, 31 edges were estimated to be non-zero $(56.36 \%)$. The network was a balanced mixture of 15 positive and 16 inverse associations (i.e., edges) that did not differ in mean absolute value $t(29)=0.75, p=0.458$. The graphical LASSO network of the higherorder global constructs is presented in Figure 1. Nodes that are more associated with one another tend to appear closer in the graph. Green lines (edges) represent positive associations, and red lines represent inverse associations. Nodes without a connecting edge are conditionally independent after partialing the rest of the nodes. ${ }^{2}$ The thickness of the edges represents the magnitude of a given partial correlation between nodes. The outer ring of each node is a pie graph projection that represents the squared multiple correlation (SMC) for the node with the nodes directly connected to it (Haslbeck \& Fried, 2017). Hence, a 90degree angle reflects $25 \%$ of shared variance between the node and those it is directly connected to. The SMCs ranged from .21 (effortful control) to .67 (PTSD and depression). The SMC for suicidal ideation was .54.

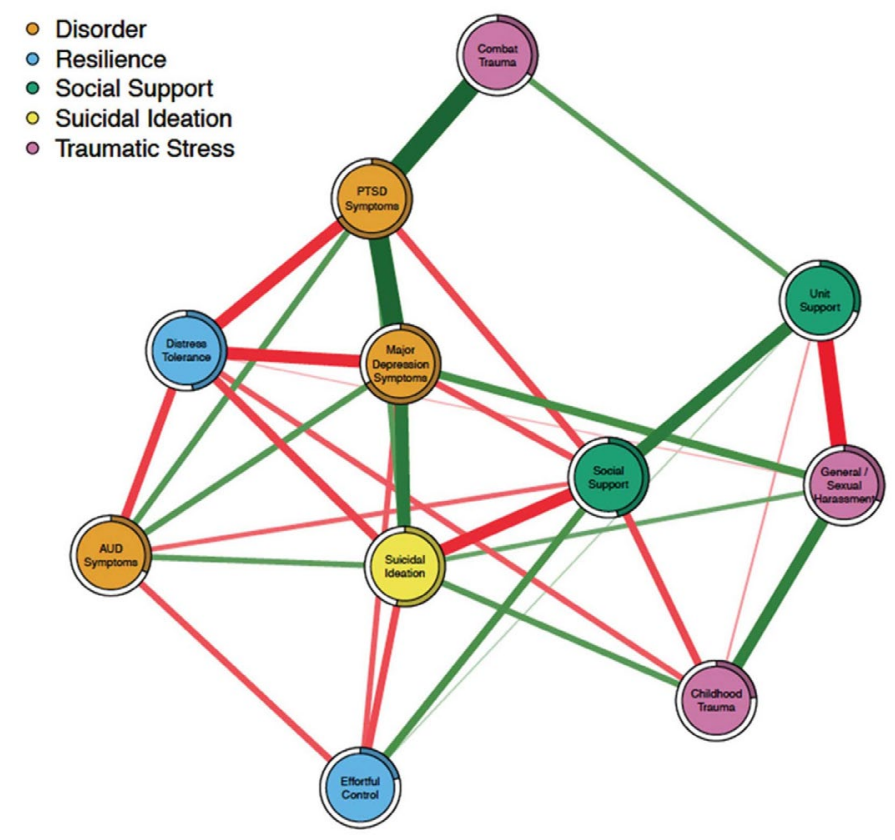

Figure 1. Network of higher-order constructs. Green edges indicate positive relationships, red edges indicate inverse relationships. The colored portion of the ring around each node indicates its squared multiple correlation based on its nonzero edge weights (e.g., a colored ring extending around $25 \%$ of the circumference is $\mathrm{SMC}=.25$ ).

As anticipated, suicidal ideation and disorder symptom nodes (i.e., Major Depression, PTSD, and AUD) were positively associated, whereas resilience (i.e., distress tolerance and effortful control) and social support exhibited inverse associations with suicidal ideation and symptoms. Combat trauma was largely connected to the rest of the network through 
its association with PTSD symptoms. In contrast, no edges appeared between childhood trauma and PTSD symptoms, depression, and AUD after regularization. This suggests that childhood trauma may be conditionally independent of PTSD symptoms, depression, and AUD. Childhood trauma was connected with the network through its positive associations with suicidal ideation and harassment and inverse associations with distress tolerance and supportive relationships with unit member, family, and friends. As expected, experiences of sexual and general harassment while deployed was strongly inversely associated with unit support. Each domain (i.e., disorder symptoms, resilience, social support, and traumatic stress) had associations with suicidal ideation.

As discussed previously, Figure 1 clearly illustrates some differences in connections between nodes. For example, effortful control exhibits a direct connection with depression symptoms but is conditionally independent of PTSD symptoms. For the nonzero edge weights, we constructed bootstrapped confidence intervals and tested differences in strength. Results indicated that the more substantial differences in edge weights are significant differences. For example, the PTSD-depression edge weight is significantly larger than the PTSD-AUD edge weight (95\% CI [0.15, 0.38]). Similarly, the unit support-social support edge weight is stronger than the unit support-effortful control edge weight $(95 \%$ CI $[-0.31,-0.06])$. However, less substantial differences in Figure 1 do not significantly differ from one another. For example, the social support-depression and social support-suicidal ideation edge weights are not significantly different (95\% CI [-0.06, 0.29]). Similarly, the depression-suicidal ideation edge and social support-suicidal ideation edge are not significantly different (95\% CI $[-0.19,0.19])$. Hence, modest differences in depicted edge weights in the figure should be interpreted with caution.

\section{Lower order constructs network}

A fully connected network with the 18 nodes of interest would have 153 edges. The LASSO procedure yielded a more parsimonious model with 80 edges $(52.29 \%)$. The resulting graphical LASSO network of the lower-order scales is presented in Figure 2. The network has 44 positive and 36 inverse edges with the mean absolute value being stronger for the positive edges $(t(78)=3.04, p=.003)$. The SMCs ranged from .24 (Childhood trauma) to .81 (PTSD-Negative alterations in cognition and mood). The SMC for suicidal ideation was .57 . 


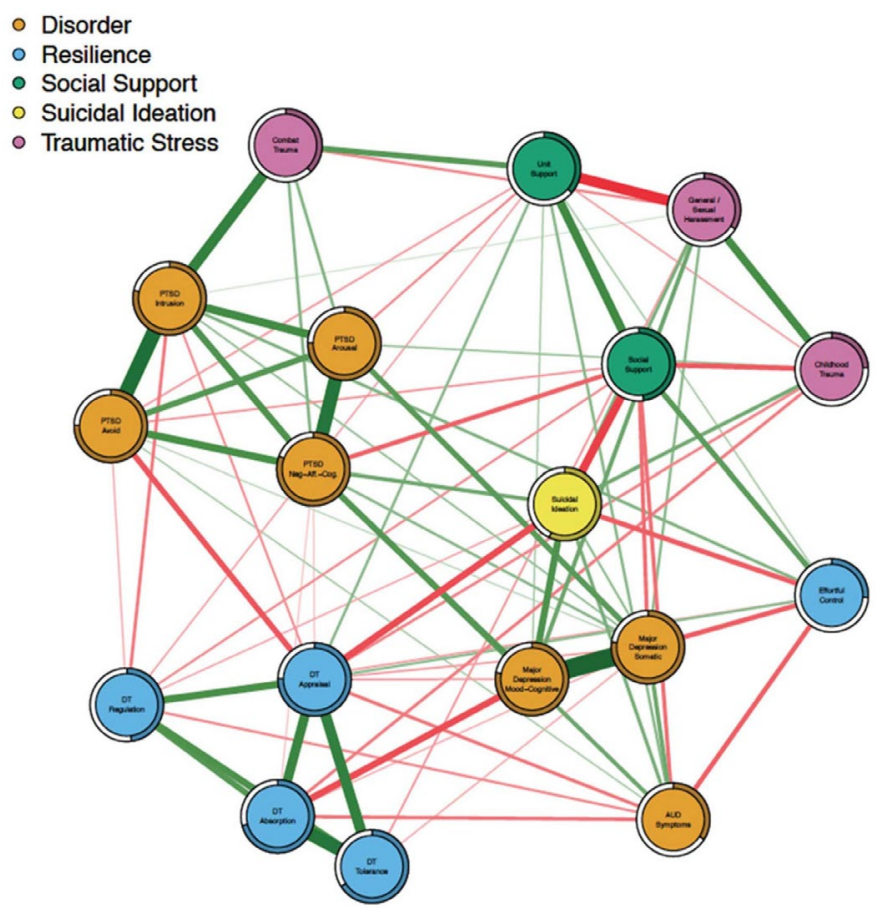

Figure 2. Network of select lower-order constructs. Green edges indicate positive relationships, red edges indicate inverse relationships. The colored portion of the ring around each node indicates its squared multiple correlation based on its nonzero edge weights (e.g., a colored ring extending around $25 \%$ of the circumference is $\mathrm{SMC}=.25$ ).

This network exhibits similar associations among domains as in the higher-order network, however, the inclusion of lower-order facets of PTSD, major depression, and distress tolerance reveals several additional findings. First, combat trauma was predominantly associated with PTSD-intrusion symptoms relative to either PTSD-arousal (95\% CI [0.08, 0.34]) or PTSD-Negative alterations in cognition and mood (95\% CI [0.10, 0.34]) and was conditionally independent of PTSD-avoidance symptoms. Second, PTSD-intrusion symptoms were more highly associated with avoidance relative to negative alterations in mood and cognition (95\% CI [0.11, 0.39]). Third, the PTSD-avoidance-DTS-Appraisal edge was one of the stronger connections between distress tolerance and PTSD symptoms. Intrusion symptoms also exhibited significant connections with both DTS regulation and appraisal. PTSD-arousal was conditionally independent of all distress tolerance facets. Fourth, childhood trauma was associated with both DTS-appraisal and absorption but was conditionally independent of the tolerance and regulation facets. Fifth, DTS-appraisal and regulation were associated with suicidal ideation, whereas the other DTS facets were conditionally independent of suicidal ideation. Finally, only the negative alterations in mood and cognition PTSD domain exhibited direct positive associations with suicidal ideation after partialling out all other nodes in the network. 


\section{Discussion}

This paper presents an innovative approach to understanding the myriad of factors associated with risk for suicide among veterans. The network analysis indicated concurrent connections between suicidal ideation and symptoms of depression, PTSD, and alcohol use disorder as well as more distal experiences of childhood trauma and sexual harassment and intimidation while deployed. In contrast, social support, effortful control, and distress tolerance had inverse connections with suicidal ideation. Importantly, the network model indicates that each of the above factors exhibits significant connections with suicidal ideation after conditioning on all other constructs in the model. Furthermore, the connections in the network model make no assumptions about directionality and hence are consistent with potential reciprocal associations between factors (e.g., AUD and depression). Though the network was constructed to increase understanding of suicide, the model highlights several other interesting associations between nodes. In the discussion below, findings are organized by domain.

\section{Psychiatric Disorder}

As expected, depression exhibited some of the strongest connections with suicidal ideation. The lower order model is consistent with previous research indicating connections with suicidal ideation are largely due to mood/cognitive rather than somatic symptoms of depression (Mitchell et al., 2017). PTSD symptoms exhibited connections with both depression and suicidal ideation. AUD exhibited positive connections with risk nodes (depression, PTSD, and suicidal ideation) as well as negative connections with distress tolerance, effortful control, and social support. Hence, excessive alcohol use remains connected with suicidal ideation after conditioning on all other network variables. This is consistent with previous research and clinical assessment guidelines that highlight substance use as an important risk factor (Darvishi et al., 2015; Department of Veterans Affairs and Department of Defense, 2013; Herberman Mash et al., 2016). Overall, the network is consistent with theoretical models indicating a wide range of reciprocal associations between AUD, social functioning, and regulation of affect and behavior (Buckner, Timpano, Zvolensky, Sachs-Ericsson, \& Schmidt, 2008; Kaiser, Bonsu, Charnigo, Milich, \& Lynam, 2016; Read, Wardell, \& Colder, 2013; Staff et al., 2010).

Our study extends previous research on network models of PTSD in several ways. First, previous studies have focused on networks of PTSD symptoms. We take a two-pronged approach to examine PTSD as a unitary node in a network of risk and resilience factors and then examine a model of lower order facets (intermediary between the symptom level and the higher-order construct). Previous research has indicated that negative alterations in cognition and mood (Cluster D) and intrusion symptoms (Cluster B) are the most central (Armour et al., 2017; Mitchell et al., 2017). However, such estimates are due, in part, to the number of symptoms and strength of correlations within the clusters (Costantini et al., 2015). In our analysis, each cluster is given equal weight (i.e., each is a single node) and the analysis shows that these clusters remain important in a network of comorbid disorders and other risk and resilience factors. However, given the focus on suicidal ideation it should 
be noted that the network still emphasizes negative affect related constructs. Hence, further research is still needed to evaluate the relative importance of negative alteration in mood and cognition in PTSD.

In addition, to the best of our knowledge, only one previous study has included criterion A (trauma exposure) in the network (Glück, Knefel, \& Lueger- Schuster, 2017). Our analysis illustrates, for the first time in a network model, that combat-related traumatic stress is predominantly connected with symptoms of intrusion (Creamer, Burgess, \& Pattison, 1992). Intrusion, in turn, exhibits strong connections with avoidance symptoms. The connection between intrusion and avoidance has been previously theorized but is less apparent in previous network models of PTSD symptoms (Armour et al., 2017; Creamer et al., 1992; Mitchell et al., 2017).

\section{Traumatic Stress}

The network analyzed in this paper takes a fairly unique perspective on the nodes relevant to understanding suicidal ideation and associated pathology in that we include both highly proximal (e.g., symptoms of depression) and quite distal factors (e.g., early childhood trauma). The results are illustrative of the long-lasting effects of childhood trauma on ability to form supportive relationships, regulate emotions, and revictimization. Indeed, the strongest connection with early childhood trauma was experience of sexual harassment and intimidation (bullying) during deployment. In addition, the inverse connections between childhood trauma and perceived support from both friends and family as well as unit members suggests that risk for suicidal ideation and vulnerability to psychopathology due to early trauma may be compounded by ongoing deficits in the ability to forge supportive social networks. Similarly, the network is consistent with Linehan's (Linehan, 1993) biopsychosocial model indicating connections between early traumatic stress and deficits in developing effective distress tolerance. Finally, sexual harassment and intimidation exhibited connections with suicidal ideation after conditioning on all other constructs. This highlights the importance of military sexual trauma and unit relationships on suicide risk, over and above major mental disorders and combat trauma.

\section{Resilience Traits}

In the higher-order model, distress tolerance had significant connections with AUD, Depression, and PTSD after conditioning on all network variables. This is consistent with conceptualizations of distress tolerance as a transdiagnostic resilience factor (Sandin et al., 2017). Distress tolerance was associated with suicidal ideation, indicating that meta-emotional factors may contribute to suicide risk over and above severity of negative emotional experience. In the lower-order model, the appraisal facet exhibited strong connections with the network. Within the distress tolerance cluster, absorption had prominent connections with affective and cognitive symptoms of depression. Effortful control had diffuse connections with several domains including both positive associations with other resilience factors (e.g., social support and unit support) as well inverse associations with depression, AUD, and suicidal ideation. Connections between effortful control and social support are consistent 
with theoretical models linking effortful control to pathology via socio-environmental factors (Wills, Simons, Sussman, \& Knight, 2016).

\section{Social Support}

Social support exhibited inverse associations with domains of traumatic stress, suicide, and disorder symptoms. These results are consistent with research indicating bidirectional relationships between social support and symptoms of depression (Agtarap et al., 2017; Liu, 2013; Stice, Ragan, \& Randall, 2004) and negative effects of childhood trauma on adult social support (Vranceanu, Hobfoll, \& Johnson, 2007). Social support was also positively associated with effortful control. Indeed, self-control has been longitudinally predictive of social competence and appropriate social behavior (Eisenberg et al., 2003; Liew, 2012). Fosco, Caruthers, and Dishion (2012) found longitudinal evidence for the reverse, namely, family support and cohesion predicting effortful control. Effective self-regulation and social support may exhibit reciprocal effects over time, jointly contributing to adaptive outcomes. Importantly, unit cohesion and combat exposure have been independently associated with increased posttraumatic growth, or, positive changes that can occur after a trauma experience (Mitchell, Gallaway, Millikan, \& Bell, 2013) and in our model, unit support exhibited inverse associations with PTSD symptom clusters.

\section{Clinical Implications}

Theory behind network analyses of psychological constructs has a host of clinical implications. For example, it has been argued that the most central symptoms in a network might be optimal treatment targets (McNally et al., 2015) and that network analyses can identify "bridge symptoms" that account for comorbidity (Cramer et al., 2010; Mitchell et al., 2017). In the current study, we highlight two primary implications. First, in the analysis of the global constructs, suicidal ideation had significant positive connections with symptoms of depression, PTSD, and AUD, as well as childhood trauma and harassment. In addition, there were inverse connections with distress tolerance, social support, and effortful control. Each of these are significant after conditioning on all other constructs in the model. Hence, prevention and intervention efforts may be most impactful by addressing multiple targets rather than a single focal presenting problem (e.g., PTSD). This is speculative given that the measured associations are inherently bidirectional and don't warrant causal interpretation. However, we think this perspective warrants consideration and that the network of associations could be maximally disrupted by simultaneously modifying multiple nodes.

Second, the network of lower order constructs highlighted the importance of PTSD intrusion symptoms in linking combat trauma with the network. Intrusion symptoms, in turn, had prominent connections with avoidance. These facets were connected with the appraisal factor of distress tolerance, which had prominent connections with other nodes and was linked to suicidal ideation. The appraisal factor of distress tolerance incorporates the ability to accept negative emotions and maintain positive self-evaluations during times of duress. This pattern of relationships between trauma, intrusions, avoidance, and acceptance 
of distress is consistent with the cognitive processing model of the genesis of PTSD (Creamer et al., 1992) and suggests that further research on transdiagnostic interventions that target emotional nonacceptance and tolerance for distress may be warranted (Fairholme, Boisseau, Ellard, Ehrenreich, \& Barlow, 2010; Gutner, Galovski, Bovin, \& Schnurr, 2016; Stephenson, Simpson, Martinez, \& Kearney, 2017; Vujanovic, Niles, Pietrefesa, Schmertz, \& Potter, 2013).

\section{Limitations}

Although our analyses provide a plethora of information regarding the complex relationships between these constructs, some inherent limitations exist. First, the sample was relatively small and precluded our ability to provide a replication of the network on a subsample or to test consistency across gender. Second, though we highlight several interesting differences in edge weights, the nonparametric bootstrap results indicate that many have overlapping confidence intervals. Furthermore, controlling for familywise error rates is not reasonable in network models (Epskamp \& Fried, 2016). Care needs to be taken to not over interpret the network graphs and pattern of associations. We have followed best practices in using bootstrapping to provide a thorough analysis of the accuracy and interpretative meaning of the network results (Costantini et al., 2015; Epskamp \& Fried, 2016). Finally, we did not include estimates of centrality such as strength. Strength estimates are calculated based on absolute values of edge weights and hence can be estimated for the current network (Borsboom \& Cramer, 2013). However, the mixture of risk and resilience factors complicates their interpretation in respect to the potential expected influence on the network.

A limitation inherent in many statistical models involves the fact that the analysis is dependent on what is or what is not included in the model. In psychology, most network models include a universe of symptoms that have been previously agreed upon. As such, to the extent that one accepts the current taxonomic system (e.g., DSM-5), those models are in some sense finite, and the nodes that compose them are known a priori. In networks like ours, which include symptoms, vulnerability, and resilience factors, defining the appropriate and accurate universe is more difficult. As with any multivariate model, the validity of the results depends, in part, on the assumption that important variables are not omitted. More research is necessary to determine what aspects are necessary and sufficient in contextualizing suicidal ideation.

\section{Summary}

Suicide is perhaps the most tragic outcome faced by veterans, their families, and their clinicians. This pressing public health problem warrants novel approaches to increase understanding of factors contributing to suicidal ideation, identify those at risk, and improve prevention and intervention to assist those who view suicide as their most viable option. The network analysis presented here highlights the myriad factors contributing to suicidal ideation. Interpersonal trauma, be it child abuse, sexual harassment, bullying, or combat trauma, exhibited connections with suicidal ideation over and above symptomatology and 
resilience factors. This highlights the importance of prevention efforts to reduce these events in society. The results are consistent with a pattern of reciprocal associations between symptoms of depression, alcohol use disorder, and PTSD, each of which exhibits connections with suicidal ideation. Tolerance for emotional distress, especially the ability to accept negative emotions and positive self-appraisal, and self-control (planning, problem solving, and goal setting) are potential modifiable resilience factors that may be targeted. Finally, positive relationships with family, friends, and unit members exhibited significant connections with all other constructs in the network. Suicidal ideation is a nexus of a complex array of factors. Prevention and intervention approaches may need to be similarly integrative, addressing multiple comorbid disorders, bolstering personal strengths and a hopeful orientation toward the future, and fostering a positive social environment.

\section{Notes}

1. An anonymous reviewer indicated problems with interpreting centrality indices given the near balance of positive and negative edge weights. As such, we took their suggestion of dispensing with global measures of centrality and focused on individual edges.

2. An anonymous reviewer pointed out that the lack of an edge between constructs does not necessarily indicate conditional independence because rejecting the null hypothesis (i.e., an effect of zero) does not imply that one can accept the null (i.e., that the association IS zero, that the constructs are conditionally independent). However, we have retained the language, as we think it most succinctly conveys the main idea of a lack of an observed significant association between two constructs after conditioning upon (partialing out) the rest of the variables.

Author Note - Data from this sample have been previously reported in Simons et al. $(2017,2018)$. The previous papers do not include the majority of constructs reported here.

Funding - This research was supported by the National Institute on Alcohol Abuse and Alcoholism of the National Institutes of Health under Award Number R01AA020519. The content is solely the responsibility of the authors and does not necessarily represent the official views of the National Institutes of Health, the Department of Veterans Affairs, or the United States Government. This research was supported with resources and the use of facilities at the Sioux Falls VA Health Care System, Bay Pines VA Health Care System, and the University of South Dakota.

\section{References}

Agtarap, S., Boals, A., Holtz, P., Roden-Foreman, K., Rainey, E. E., Ruggero, C., \& Warren, A. M. (2017). The effect of depressive symptoms on social support one year following traumatic injury. Journal of Affective Disorders, 207, 398-405. doi:10.1016/j.jad.2016.08.067

American Psychiatric Association (2013). Diagnostic and statistical manual of mental disorders (5th ed.). Washington, DC: American Psychiatric Association.

Anestis, M. D., Bagge, C. L., Tull, M. T., \& Joiner, T. E. (2011). Clarifying the role of emotion dysregulation in the interpersonal-psychological theory of suicidal behavior in an undergraduate sample. Journal of Psychiatric Research, 45(5), 603-611. doi:10.1016/j.jpsychires.2010.10.013 
Anker, J. J., Forbes, M. K., Almquist, Z. W., Menk, J. S., Thuras, P., Unruh, A. S., \& Kushner, M. G. (2017). A network approach to modeling comorbid internalizing and alcohol use disorders. Journal of Abnormal Psychology, 126(3), 325-339. doi:10.1037/abn0000257

Armour, C., Fried, E. I., Deserno, M. K., Tsai, J., \& Pietrzak, R. H. (2017). A network analysis of DSM5 posttraumatic stress disorder symptoms and correlates in U.S. military veterans. Journal of Anxiety Disorders, 45, 49-59. doi:10.1016/j.janxdis.2016.11.008

Aupperle, R. L., Melrose, A. J., Stein, M. B., \& Paulus, M. P. (2012). Executive function and PTSD: disengaging from trauma. Neuropharmacology, 62(2), 686-694. doi: 10.1016/j.neuropharm.2011.02.008

Blanchard, E. B., Jones-Alexander, J., Buckley, T. C., \& Forneris, C. A. (1996). Psychometric properties of the PTSD Checklist (PCL). Behaviour Research and Therapy, 34(8), 669-673. doi:10.1037/pas0000254

Borsboom, D. (2017). A network theory of mental disorders. World Psychiatry, 16(1), 5-13. doi: 10.1002/ wps. 20375

Borsboom, D., \& Cramer, A. O. (2013). Network analysis: an integrative approach to the structure of psychopathology. Annual Review of Clinical Psychology, 9(1), 91-121. doi:10.1146/annurevclinpsy050212-185608

Borsboom, D., Cramer, A. O., Schmittmann, V. D., Epskamp, S., \& Waldorp, L. J. (2011). The small world of psychopathology. PLoS ONE, 6(11), e27407. doi:10.1371/journal.pone.0027407

Bryan, C. J., Garland, E. L., \& Rudd, M. D. (2016). From impulse to action among military personnel hospitalized for suicide risk: alcohol consumption and the reported transition from suicidal thought to behavior. General Hospital Psychiatry, 41, 13-19. doi:10.1016/j.genhosppsych.2016.05.001

Bryant, R. A., Creamer, M., O’Donnell, M., Forbes, D., McFarlane, A. C., Silove, D., \& Hadzi-Pavlovic, D. (2017). Acute and chronic posttraumatic stress symptoms in the emergence of posttraumatic stress disorder: A network analysis. JAMA Psychiatry, 74(2), 135-142. doi: 10.1001/jamapsychiatry .2016 .3470

Buckner, J. D., Timpano, K. R., Zvolensky, M. J., Sachs-Ericsson, N., \& Schmidt, N. B. (2008). Implications of comorbid alcohol dependence among individuals with social anxiety disorder. Depression and Anxiety, 25(12), 1028-1037. doi: 10.1002/da.20442

Costantini, G., Epskamp, S., Borsboom, D., Perugini, M., Mõttus, R., Waldorp, L. J., \& Cramer, A. O. J. (2015). State of the aRt personality research: A tutorial on network analysis of personality data in R. Journal of Research in Personality, 54, 13-29. doi: 10.1016/j.jpp.2014.07.003

Cramer, A. O., Waldorp, L. J., van der Maas, H. L., \& Borsboom, D. (2010). Comorbidity: A network perspective. Behavioral and Brain Sciences, 33(2-3), 137-150; discussion 150-93. doi: 10.1017/S0140525 X09991567

Creamer, M., Burgess, P., \& Pattison, P. (1992). Reaction to trauma: a cognitive processing model. Journal of Abnormal Psychology, 101(3), 452-459. doi: 10.1037//0021-843X.101.3.452

Darvishi, N., Farhadi, M., Haghtalab, T., \& Poorolajal, J. (2015). Alcohol-related risk of suicidal ideation, suicide attempt, and completed suicide: A meta-analysis. PLoS One, 10(5), e0126870. doi: 10.1371/journal.pone.0126870

de Beurs, D. (2017). Network analysis: a novel approach to understand suicidal behaviour. International Journal of Environmental Research and Public Health, 14(3), 219. doi:10.3390/ijerph14030219

de Beurs, D. P., van Borkulo, C. D., \& O'Connor, R. C. (2017). Association between suicidal symptoms and repeat suicidal behaviour within a sample of hospital-treated suicide attempters. Bjpsych Open, 3(3), 120-126. doi: 10.1192/bjpo.bp.116.004275

Department of Veterans Affairs and Department of Defense (2013). VA/DOD clinical practice guideline for assessment and management of patients at risk for suicide. Retrieved from https://www .healthquality.va.gov/guidelines/MH/srb/VADODCP_SuicideRisk_Full.pdf. 
Doyle, S. R., \& Donovan, D. M. (2009). A validation study of the alcohol dependence scale. Journal of Studies on Alcohol and Drugs, 70(5), 689-699. doi: 10.15288/jsad.2009.70.689

Eaton, W. W., Smith, C., Ybarra, M., Muntaner, C., \& Tien, A. (2004). Center for Epidemiologic Studies Depression Scale: Review and revision (CESD and CESD-R). In M. Maruish (Ed.), The use of psychological testing for treatment planning and outcomes assessment (3rd ed., pp. 363-377). Mahwah, NJ: Lawrence Erlbaum.

Eisenberg, N., Valiente, C., Fabes, R. A., Smith, C. L., Reiser, M., Shepard, S. A., . . Cumberland, A. J. (2003). The relations of effortful control and ego control to children's resiliency and social functioning. Developmental Psychology, 39(4), 761-776. doi: 10.1037/0012-1649.39.4.761

Elhai, J. D., Contractor, A. A., Tamburrino, M., Fine, T. H., Prescott, M. R., Shirley, E., . . Calabrese, J. R. (2012). The factor structure of major depression symptoms: a test of four competing models using the Patient Health Questionnaire-9. Psychiatry Research, 199(3), 169-173. doi: 10.1016/j.psychres .2012.05.018

Epskamp, S., Borsboom, D., \& Fried, E. I. (2018). Estimating psychological networks and their accuracy: A tutorial paper. Behavior Research Methods, 50, 195-212. doi: 10.3758/s13428-017-0862-1

Epskamp, S., Cramer, A. O. J., Waldorp, L. J., Schmittmann, V. D., \& Borsboom, D. (2012). qgraph: Network visualizations of relationships in psychometric data. Journal of Statistical Software, 48, 1-18.

Epskamp, S., \& Fried, E. I. (2016). A tutorial on regularized partial correlation networks. arXiv Preprint arXiv, 1607, 01367.

Fairholme, C. P., Boisseau, C. L., Ellard, K. K., Ehrenreich, J. T., \& Barlow, D. H. (2010). Emotions, emotion regulation, and psychological treatment: A unified perspective. In A. M. Kring, D. M. Sloan, A. M. Kring, \& D. M. Sloan (Eds.), Emotion regulation and psychopathology: A transdiagnostic approach to etiology and treatment (pp. 283-309). New York, NY: Guilford Press.

Fosco, G. M., Caruthers, A. S., \& Dishion, T. J. (2012). A six-year predictive test of adolescent family relationship quality and effortful control pathways to emerging adult social and emotional health. Journal of Family Psychology, 26(4), 565-575. doi: 10.1037/a0028873

Franklin, J. C., Ribeiro, J. D., Fox, K. R., Bentley, K. H., Kleiman, E. M., Huang, X., . . Nock, M. K. (2017). Risk factors for suicidal thoughts and behaviors: A meta-analysis of 50 years of research. Psychological Bulletin, 143(2), 187-232. doi: 10.1037/bul0000084

Gibbons, R. D., Brown, C. H., \& Hur, K. (2012). Is the rate of suicide among veterans elevated? American Journal of Public Health, 102(S1), S17-S19. doi: 10.2105/AJPH.2011.300491

Glück, T. M., Knefel, M., \& Lueger-Schuster, B. (2017). A network analysis of anger, shame, proposed ICD-11 posttraumatic stress disorder, and different types of childhood trauma in foster care settings in a sample of adult survivors. Eur J Psychotraumatol, 8(sup3), 1372543. doi: 10.1080/20008198 .2017 .1372543

Griffith, J. (2015). Cross (Unit)-level effects of cohesion on relationships of suicide thoughts to combat exposure, postdeployment stressors, and postdeployment social support. Behavioral Medicine, 41(3), 98-106. doi: 10.1080/08964289.2014.987719

Guerra, V. S., \& Calhoun, P. S. (2011). Examining the relation between posttraumatic stress disorder and suicidal ideation in an OEF/OIF veteran sample. Journal of Anxiety Disorders, 25(1), 12-18. doi: 10.1016/j.janxdis.2010.06.025

Gutner, C. A., Galovski, T., Bovin, M. J., \& Schnurr, P. P. (2016). Emergence of transdiagnostic treatments for PTSD and posttraumatic distress. Current Psychiatry Reports, 18, 95. doi: 10.1007/s11920016-0734-x 
Hahn, A. M., Tirabassi, C. K., Simons, R. M., \& Simons, J. S. (2015). Military sexual trauma, combat exposure, and negative urgency as independent predictors of PTSD and subsequent alcohol problems among OEF/OIF veterans. Psychological Services, 12(4), 378-383. doi: 10.1037/ser0000060

Haslbeck, J. M. B., \& Fried, E. I. (2017). How predictable are symptoms in psychopathological networks? A reanalysis of 18 published datasets. Psychological Medicine, 47, 1-10. doi: 10.1017/ S0033291717001258

Herberman Mash, H. B., Fullerton, C. S., Ng, T. H., Nock, M. K., Wynn, G. H., \& Ursano, R. J. (2016). Alcohol use and reasons for drinking as risk factors for suicidal behavior in the U.S. Army. Military Medicine, 181(8), 811-820. doi: 10.7205/MILMED-D-15-00122

Jones, P. J., Heeren, A., \& McNally, R. J. (2017). Commentary: A network theory of mental disorders. Frontiers in Psychology, 8, 1305. doi: 10.3389/fpsyg.2017.01305

Kaiser, A., Bonsu, J. A., Charnigo, R. J., Milich, R., \& Lynam, D. R. (2016). Impulsive personality and alcohol use: Bidirectional relations over one year. Journal of Studies on Alcohol and Drugs, 77(3), 473-482. doi: 10.15288/jsad.2016.77.473

Kaplan, M. S., Huguet, N., McFarland, B. H., \& Newsom, J. T. (2007). Suicide among male veterans: A prospective population-based study. Journal of Epidemiology and Community Health, 61(7), 619624. doi: 10.1136/jech.2006.054346

Kendall, P. C., \& Williams, C. L. (1982). Assessing the cognitive and behavioral components of children's self-management. In P. Karoly \& F. H. Kanfer (Eds.), Self-management and behavior change (pp. 240-284). New York, NY: Pergamon Press.

Kessler, R. C., Warner, C. H., Ivany, C., Petukhova, M. V., Rose, S., Bromet, E. J., . . Ursano, R. J. (2015). Predicting U.S. Army suicides after hospitalizations with psychiatric diagnoses in the Army Study to Assess Risk and Resilience in Servicemembers (Army STARRS). JAMA Psychiatry, 72(1), 49-57. doi: 10.1001/jamapsychiatry.2014.1754

Kleiman, E. M., Liu, R. T., \& Riskind, J. H. (2014). Integrating the interpersonal psychological theory of suicide into the depression/suicidal ideation relationship: A short-term prospective study. Behavior Therapy, 45(2), 212-221. doi: 10.1016/j.beth.2013.10.007

Kleiman, E. M., Riskind, J. H., \& Schaefer, K. E. (2014). Social support and positive events as suicide resiliency factors: Examination of synergistic buffering effects. Archives of Suicide Research, 18(2), 144-155. doi: 10.1080/13811118.2013.826155

Kline, R. B. (2016). Principles and practices of structural equation modeling (4th ed). New York, NY: Guilford.

Klonsky, E. D., \& May, A. (2010). Rethinking impulsivity in suicide. Suicide and Life-Threatening Behavior, 40(6), 612-619. doi: 10.1521/suli.2010.40.6.612

Krysinska, K., \& Lester, D. (2010). Posttraumatic stress disorder and suicide risk: A systematic review. Archives of Suicide Research, 14(1), 1-23. doi: 10.1080/13811110903478997

Leyro, T. M., Bernstein, A., Vujanovic, A. A., McLeish, A. C., \& Zvolensky, M. J. (2011). Distress tolerance scale: A confirmatory factor analysis among daily cigarette smokers. Journal of Psychopathology and Behavioral Assessment, 33(1), 47-57. doi: 10.1007/s10862-010-9197-2

Liew, J. (2012). Effortful control, executive functions, and education: Bringing self-regulatory and social-emotional competencies to the table. Child Development Perspectives, 6(2), 105-111. doi: 10.1111/ j.1750-8606.2011.00196.x

Linehan, M. M. (1993). Cognitive-behavioral treatment of borderline personality disorder. New York, NY: Guilford Press.

Liu, R. T. (2013). Stress generation: Future directions and clinical implications. Clinical Psychology Review, 33(3), 406-416. doi: 10.1016/j.cpr.2013.01.005 
Liu, R. T., \& Alloy, L. B. (2010). Stress generation in depression: A systematic review of the empirical literature and recommendations for future study. Clinical Psychology Review, 30(5), 582-593. doi: 10.1016/j.cpr.2010.04.010

Marshall-Berenz, E. C., Vujanovic, A. A., Bonn-Miller, M. O., Bernstein, A., \& Zvolensky, M. J. (2010). Multimethod study of distress tolerance and PTSD symptom severity in a trauma-exposed community sample. Journal of Traumatic Stress, 23(5), 623-630. doi: 10.1002/jts.20568

Mash, H. B. H., Naifeh, J. A., Fullerton, C. S., Morganstein, J. C., \& Ursano, R. J. (2018). Suicidal behaviors in military and veteran populations: Risk factors and strategies for prevention and intervention. In L. Roberts \& C. Warner (Eds.), Military and veteran mental health (pp. 401-419). New York, NY: Springer.

McNally, R. J., Robinaugh, D. J., Wu, G. W., Wang, L., Deserno, M. K., \& Borsboom, D. (2015). Mental disorders as causal systems: A network approach to posttraumatic stress disorder. Clinical Psychological Science, 3(6), 836-849. doi: 10.1177/2167702614553230

Miller, A. B., Esposito-Smythers, C., \& Leichtweis, R. N. (2015). Role of social support in adolescent suicidal ideation and suicide attempts. Journal of Adolescent Health, 56(3), 286-292. doi: 10.1016/ j.jadohealth.2014.10.265

Miller, M., Barber, C., Young, M., Azrael, D., Mukamal, K., \& Lawler, E. (2012). Veterans and suicide: A reexamination of the National Death Index-linked National Health Interview Survey. American Journal of Public Health, 102(S1), S154-S159. doi: 10.2105/AJPH.2011.300409

Mitchell, K. S., Wolf, E. J., Bovin, M. J., Lee, L. O., Green, J. D., Rosen, R. C., . . Marx, B. P. (2017). Network models of DSM-5 posttraumatic stress disorder: Implications for ICD-11. Journal of Abnormal Psychology, 126(3), 355-366. doi: 10.1037/abn0000252

Mitchell, M. M., Gallaway, M. S., Millikan, A. M., \& Bell, M. R. (2013). Combat exposure, unit cohesion, and demographic characteristics of soldiers reporting posttraumatic growth. Journal of Loss and Trauma, 18(5), 383-395. doi: 10.1080/15325024.2013.768847

National Center for Health Statistics (2017). Health, United States, 2016: With Chartbook on long-term trends in health. Hyattsville, MD: U.S. Department of Health and Human Services. Centers for Disease Control and Prevention.

Neal, D. J., \& Carey, K. B. (2005). A follow-up psychometric analysis of the self-regulation questionnaire. Psychology of Addictive Behaviors, 19(4), 414-422. doi: 10.1037/0893-164X.19.4.414

Olbert, C. M., Gala, G. J., \& Tupler, L. A. (2014). Quantifying heterogeneity attributable to polythetic diagnostic criteria: Theoretical framework and empirical application. Journal of Abnormal Psychology, 123(2), 452-462. doi: 10.1037/a0036068

Pearl, J. (1998). Graphs, causality, and structural equation models. Sociological Methods E Research, 27, 226-284. doi: 10.1177/0049124198027002004

Pessoa, L. (2009). How do emotion and motivation direct executive control? Trends in Cognitive Sciences, 13(4), 160-166. doi: 10.1016/j.tics.2009.01.006

Pfeiffer, P. N., Ganoczy, D., Ilgen, M., Zivin, K., \& Valenstein, M. (2009). Comorbid anxiety as a suicide risk factor among depressed veterans. Depression and Anxiety, 26(8), 752-757. doi: 10.1002/ da. 20583

Pietrzak, R. H., Johnson, D. C., Goldstein, M. B., Malley, J. C., Rivers, A. J., Morgan, C. A., \& Southwick, S. M. (2010). Psychosocial buffers of traumatic stress, depressive symptoms, and psychosocial difficulties in veterans of Operations Enduring Freedom and Iraqi Freedom: The role of resilience, unit support, and postdeployment social support. Journal of Affective Disorders, 120(1-3), 188-192. doi: 10.1016/j.jad.2009.04.015 
Pompili, M., Serafini, G., Innamorati, M., Dominici, G., Ferracuti, S., Kotzalidis, G. D., . . Lester, D. (2010). Suicidal behavior and alcohol abuse. International Journal of Environmental Research and Public Health, 7(4), 1392-1431. doi: 10.3390/ijerph7041392

Poorolajal, J., Haghtalab, T., Farhadi, M., \& Darvishi, N. (2016). Substance use disorder and risk of suicidal ideation, suicide attempt and suicide death: A meta-analysis. Journal of Public Health, 38(3), e282-e291. doi: 10.1093/pubmed/fdv148

Read, J. P., Wardell, J. D., \& Colder, C. R. (2013). Reciprocal associations between PTSD symptoms and alcohol involvement in college: A three-year trait-state-error analysis. Journal of Abnormal Psychology, 122(4), 984-997. doi: 10.1037/a0034918

Robinaugh, D. J., Millner, A. J., \& McNally, R. J. (2016). Identifying highly influential nodes in the complicated grief network. Journal of Abnormal Psychology, 125(6), 747-757. doi: 10.1037/abn0000181

Rudd, M. D. (2014). Core competencies, warning signs, and a framework for suicide risk assessment in clinical practice. In M. K. Nock (Ed.), Oxford library of psychology. The Oxford handbook of suicide and self-injury (pp. 323-336). New York, NY, US: Oxford University Press.

Sandin, B., Simons, J. S., Valiente, R. M., Simons, R. M., \& Chorot, P. (2017). Psychometric properties of the spanish version of The Distress Tolerance Scale and its relationship with personality and psychopathological symptoms. Psicothema, 29, 421-428. doi: 10.7334/psicothema2016.239

Schoenbaum, M., Kessler, R. C., Gilman, S. E., Colpe, L. J., Heeringa, S. G., Stein, M. B., . . Cox, K. L. (2014). Predictors of suicide and accident death in the Army Study to Assess Risk and Resilience in Servicemembers (Army STARRS): Results from the Army Study to Assess Risk and Resilience in Servicemembers (Army STARRS). JAMA Psychiatry, 71(5), 493-503. doi:10.1001/jamapsychiatry .2013. 4417

Schuckit, M. A., Smith, T. L., \& Kalmijn, J. (2013). Relationships among independent major depressions, alcohol use, and other substance use and related problems over 30 years in 397 families. Journal of Studies on Alcohol and Drugs, 74(2), 271-279. doi: 10.15288/jsad.2013.74.271

Simons, J. S., \& Gaher, R. M. (2005). The Distress Tolerance Scale: Development and validation of a self-report measure. Motivation and Emotion, 29(2), 83-102. doi: 10.1007/s11031-005-7955-3

Simons, J. S., Simons, R. M., Keith, J. A., Grimm, K. J., Stoltenberg, S. F., O’Brien, C., \& Andal, K. (2018). PTSD symptoms and alcohol-related problems among veterans: Temporal associations and vulnerability. Journal of Abnormal Psychology, 127, 733-750. doi: 10.1037/abn0000376

Simons, J. S., Simons, R. M., O’Brien, C., Stoltenberg, S. F., Keith, J. A., \& Hudson, J. A. (2017). PTSD, alcohol dependence, and conduct problems: Distinct pathways via lability and disinhibition. Addictive Behaviors, 64, 185-193. doi: 10.1016/j.addbeh.2016.08.044

Simons, J. S., Wills, T. A., Emery, N. N., \& Spelman, P. J. (2016). Keep calm and carry on: Maintaining self-control when intoxicated, upset, or depleted. Cognition and Emotion, 30, 1415-1429. doi: 10.1080/ 02699931.2015. 1069733

Skinner, H. A., \& Allen, B. A. (1982). Alcohol dependence syndrome: Measurement and validation. Journal of Abnormal Psychology, 91(3), 199-209. doi: 10.1037//0021-843X.91.3.199

Skinner, H. A., \& Horn, J. L. (1984). Alcohol dependence scale: User's guide. Retrieved from Toronto.

Smith, S. M., Goldstein, R. B., \& Grant, B. F. (2016). The Association Between Posttraumatic Stress Disorder and Lifetime DSM-5 Psychiatric Disorders among Veterans: Data from the National Epidemiologic Survey on Alcohol and Related Conditions-III (NESARC-III). Journal of Psychiatric Research, 82, 16-22. doi: 10.1016/j.jpsychires.2016.06.022

Staff, J., Schulenberg, J. E., Maslowsky, J., Bachman, J. G., O’Malley, P. M., Maggs, J. L., \& Johnston, L. D. (2010). Substance use changes and social role transitions: Proximal developmental effects 
on ongoing trajectories from late adolescence through early adulthood. Development and Psychopathology, 22(04), 917-932. doi: 10.1017/S0954579410000544

Stephenson, K. R., Simpson, T. L., Martinez, M. E., \& Kearney, D. J. (2017). Changes in mindfulness and posttraumatic stress disorder symptoms among veterans enrolled in mindfulness-based stress reduction. Journal of Clinical Psychology, 73(3), 201-217. doi: 10.1002/jclp.22323202

Stice, E., Ragan, J., \& Randall, P. (2004). Prospective relations between social support and depression: Differential direction of effects for parent and peer support? Journal of Abnormal Psychology, 113(1), 155-159. doi: 10.1037/0021-843X.113.1.155

Tibshirani, R. (1996). Regression shrinkage and selection via the lasso. Journal of the Royal Statistical Society. Series B (Methodological), 58(1), 267-288. doi: 10.1111/j.2517-6161.1996.tb02080.x

Troister, T., Links, P. S., \& Cutcliffe, J. (2008). Review of predictors of suicide within 1 year of discharge from a psychiatric hospital. Current Psychiatry Reports, 10(1), 60-65. doi: 10.1007/s11920008-0011-8

U.S. Department of Veteran Affairs (2012). Using the PTSD Checklist (PCL). Retrieved from http://www.ptsd.va.gov/professional/pages/assessments/ptsd-checklist.asp.

U.S. Department of Veteran Affairs (2017). Suicide among veterans and other Americans. Washington, DC: Office of Mental Health and Suicide Prevention.

Vogt, D., Smith, B., King, D., \& King, L. (2012). Manual for the Deployment Risk and Resilience Inventory2 (DRRI-2): A collection of measures for studying deployment-related experiences of military veterans. Boston, MA: National Center for PTSD.

Vranceanu, A.-M., Hobfoll, S. E., \& Johnson, R. J. (2007). Child multi-type maltreatment and associated depression and PTSD symptoms: The role of social support and stress. Child Abuse and Neglect, 31(1), 71-84. doi: 10.1016/j.chiabu.2006.04.010

Vujanovic, A. A., Marshall-Berenz, E. C., \& Zvolensky, M. J. (2011). Posttraumatic stress and alcohol use motives: A test of the incremental and mediating role of distress tolerance. Journal of Cognitive Psychotherapy, 25(2), 130-141. doi: 10.1891/0889-8391.25.2.130

Vujanovic, A. A., Niles, B., Pietrefesa, A., Schmertz, S. K., \& Potter, C. M. (2013). Mindfulness in the treatment of posttraumatic stress disorder among military veterans. Spirituality in Clinical Practice, 1, 15-25. doi: 10.1037/2326-4500.1.S.15

Weathers, F., Litz, B., Herman, D., Huska, J., \& Keane, T. (1993). The PTSD checklist (PCL): Reliability, validity, and diagnostic utility. Paper presented at the International Society of Traumatic Stress Studies, San Antonio, TX. http://www.pdhealth.mil/library/downloads/PCL_sychometrics.doc

Wills, T. A., Cleary, S., Filer, M., Shinar, O., Mariani, J., \& Spera, K. (2001). Temperament related to early-onset substance use: test of a developmental model. Prevention Science, 2(3), 145-163. doi: 10.1023/A:1011558807062

Wills, T. A., Simons, J. S., Sussman, S., \& Knight, R. (2016). Emotional self-control and dysregulation: A dual-process analysis of pathways to externalizing/internalizing symptomatology and positive well-being in younger adolescents. Drug and Alcohol Dependence, 163 (Suppl 1), S37-S45. doi: 10.1016/j.drugalcdep.2015.08.039

Zivin, K., Kim, H. M., McCarthy, J. F., Austin, K. L., Hoggatt, K. J., Walters, H., \& Valenstein, M. (2007). Suicide mortality among individuals receiving treatment for depression in the veterans affairs health system: Associations with patient and treatment setting characteristics. American Journal of Public Health, 97(12), 2193-2198. doi: 10.2105/AJPH.2007.115477 